\title{
Reforming Higher Education in India: In Pursuit of Excellence
}

\author{
Chetan Singai $^{1,3}$, T R Kumaraswamy ${ }^{2}$, Ajay Chandra ${ }^{3}$ \\ ${ }^{1}$ Ramaiah College of Law, ${ }^{2}$ Bangalore University, ${ }^{3}$ Ramaiah Public Policy Center, India.
}

\begin{abstract}
Higher education has emerged as one of the most critical factors for the Nation's economic, political, social and cultural growth and development. Reforming the higher education sector has become an emergent norm across the globe, especially in the developing world. India is one such emerging Nation, witnessing a significant shift in its ideological, pragmatic and policy directions in the last few years. The higher education sector in India has seen unprecedented expansion. However, given the distinctive social-politicaleconomic context and its complexity in India, expansion in higher education is often linked with ensuring equity and access. Whereas in the developed world, expansion is often associated with quality or excellence in higher education, i.e. creating world-class universities. Further, excellence in higher education is arguably the most critical component for the survival, sustenance and growth of the sector.

To this end, the paper examines the convergence and divergence in policies and practices related to the pursuit of excellence in higher education and its institutions in India vis-à-vis the dominant global reforms in higher education. Erstwhile policies related to quality in higher education and the current draft National Education Policy-2019, provide a reference to the local-distinctive strategies for seeking excellence at the systemic and the institutional level, with an aspiration for global reputation. For instance, National Institutional Ranking Framework, University Grants Commission's graded autonomy, Institutional restructuring, National Accreditation and Assessment Council and Quacquarelli Symonds - India rating, and so on. The paper also sets direction on how local strategies for global aspirations could unpack a series of issues regarding the reforms in education and delineate in what ways that these emerging global reforms, strategies are effective and appropriate to the local higher education system and its institutions.
\end{abstract}

Keywords: Excellence, Systemic and Institutional Level, Internationalization and World-Class University. 


\section{Introduction}

Globalization and internationalization have been one of the key factors in changing the landscape of higher education in India. When the Nation is revisiting its national education policy, after more than three decades, it is important to analyze the role and relevance of higher education for a developing economy and society. Since independence, higher education in the country has witnessed unprecedented expansion and demand amongst stakeholders and has led the institutions to compete and sustain. In the last half-a-decade, quality and excellence have been the core parameters for institutions to compete and sustain.

Critical reforms to ensure equity, expansion and excellence (Ramaprasad and Singai et al., 2016) have transformed the higher education in terms of access, practices and governance. Universities and higher education institutions are involved in constant aspiration to emerge as world-class universities. Several policy reforms and institutional arrangements have further aided to integrate into the process of quality assurance and quality enhancement. Internationalization and globalization of higher education both at the regional and national levels is one such instance. Such approaches often include measures to harness competence, cooperation, collaboration and creativity in research, teaching and service amongst the HEIs. Further, the global and national ranking, rating and national accreditation systems have a substantial impact on the decision-making ability of institutions and the stakeholders in higher education. OECD studies (2014) have found that 63 percent of responding institutions have taken strategic organizational, managerial, or academic actions in response to accreditations, rankings and ratings.

\subsection{Defining a world-class university}

Attaining quality improvements and embedding a quality culture could be concentrated around one of the core activities of universities (Lomas, 2004) such as teaching, research and extension. World-class universities are mainly characterized as a research-intensive university with world-class capacity. An emerging international knowledge economy often depends on 'world-class universities capacity' to harness competitiveness.

Reforms to achieve research excellence is mainly carried out to develop the universities' governance, in terms of administration, management, and staff capacity. Along with this, the concept of a world-class university cannot exist without the 'internationalization' (Li and Chen, 2011). Fitness for purpose in higher education has been considered the most widely adopted approach to evaluate quality. Today, global and national ranking, rating and accreditation systems assert a pivotal role in influencing the choices of stakeholders in higher education. These mechanisms may assist in planning future directions, develop and review the courses and academic programmes, handle student assessment, enhance the 
quality of information, academic standards and achievements. Quality evaluations often emphasize on meeting the objectives, documentation and using institutional quality mechanisms to determine and maintain standards, all of which are reflections of quality and accountability, which could foster excellence.

In the last few decades, assessment and evaluation of Higher Education Institutions (HEIs) have taken myriad forms. For instance, national and international accreditation, ranking and rating are the most dominant forms at the national, regional and international levels. The primary objective of such an assessment is to ensure the evaluation and implementation of quality assurance processes or excellence in HEIs.

Higher education across the globe has evolved into an industry and service, appealing to masses and respective government and non-government entities. The notion of accountability is central to HEIs, and the value for money is closely interlinked with the ideology that education should contribute to the scientific, technological, informational, social and cultural advancements. In this context, accreditation, ranking and rating systems have been the main instruments of measuring quality and standards among HEIs. Rating and the process of accreditation differ in their methodology, outcome and orientation. Both rating and accreditation in higher education assign a particular grade to an institution based on certain thresholds and pre-defined criteria.

To this end, an institution can undertake a self-assessment by itself; however, the legitimacy and objectivity of such an assessment ought to be problematic for the institution per se and the milieu. To avoid internal prejudices and stakeholders' undue influences, generally, an external agency, which is supposed to be autonomous and trustworthy, is entrusted with the responsibility of assessing the quality of an HEIs. The term "External Quality Assurance" refers to all forms of quality monitoring, evaluation or review (Martin and Stella 2007). Given this procedure, HEIs could engage in examining their strengths and weaknesses along with core drivers and barriers for achieving excellence.

The concept of quality and excellence can be used as a competitive tool, which could result in a profit and the culture of consumerism. For instance, the internationalization of higher education would act as a link between the labor market and HEIs. Given the competition, run-of-the-mill institutions will try their level to become the best, and those who eventually fail to respond to the competition will have to eventually close down. For instance, students being one of the main stakeholders would often prefer to chose institutions based on their performance in teaching, research and/or service. In such a competitive environment, every institution would aspire to improve their quality, which eventually precedes to an improvement in the perfoance of the institution in particular and the overall landscape of the higher education sector. To this end, national and international accreditation, rating and ranking are preferred means of determining institution's excellence. 
However, despite its reputation over the past decade, global university rankings and ratings have been critiqued on data, methodological and local relevance flaws from many academicians (Bekhradnia 2016; Soh, 2017). Their measure of excellence lays emphasis on high impact research and internationalization, which may not be appropriate to the countries in the developing world. Existing ranking, ratings and assessment mechanisms are crucial for examining the status- quo of HEIs and ought to be functional for long in the Indian context. Further, given the distinct methodologies and outcomes of these mechanisms, HEIs ought to adopt both. While ranking benchmarks an institution globally, regionally and locally in a comparative perspective for the stakeholders, rating givens an indepth understanding of an institution's quality parameters. Hence, HEIs should perceive that both the ranking and the rating methodology as mutually inclusive entities.

\section{Higher Education in India - In Pursuit of Excellence}

The Indian higher education system one of the most significant systems in the world. Since independence, there has been a substantial expansion in Indian higher education. The Nation has witnessed enormous growth in the number of Higher Education Institutions (HEIs) across the country. The number of Universities in the country has increased from 32 in 1950-51 to and 993 in 2018-2019, which denotes more than a forty-six folds increase. Similarly, the number of colleges has gone up from 695 to 39931 (UGC, 2003; Agarwal, 2007; AISHE, 2019). National policies such as the 'Right to Education Act', which insist on compulsory and free education to all children within the age groups of 6-14 years, has resulted in an upsurge in enrolment at the secondary level in the last decade. In other words, students successfully completing secondary education is considered as a primary reason for the increasing demand for enrolment in higher education. As a result of this, the country has witnessed an unprecedented expansion of higher education institutions across the country (Shaguri, 2013).

The last decade has witnessed a massive enrolment in higher education, and it has increased from 29.8 Lakh in 1980-1981 to 373.9 lakh in 2018-2019. Also, over 70 percent of HEIs in India is managed by the private sector, and they cater to more than 70 percent of student's enrolment (AISHE 2019). It also aims to increases its gross enrolment ratio to 30 percent by 2020 -2021from the current 26.3 percent. Post-independence, the Government of India has focused on expansion and equity in higher education. Despite the substantial and astonishing improvement in the past decade, the Indian higher education sector still deals with significant challenges in qualitative terms. For instance, the National Knowledge Commission's "Report to the Nation" reckons that the 'crisis in Higher education in India runs deeper' and suggests the need for improving its overall quality (NKC, 2006). 
In India, quality assurance mechanisms in higher education in India is undertaken by a few popular agencies listed below:

a) National Assessment and Accreditation Council (NAAC) - established in 1994

b) National Board of Accreditation (NBA) - established in 1994

c) Quacquarelli Symonds and Times Higher Education World University Rankings established in 1990 and 2010 respectively

d) QS I.GAUGE Ratings - established in 2018

At the local level, the process of accreditation, rankings and ratings are strongly driven by data and evidence. These methodologies have a set of indicators, which can be assessed quantitatively, often claiming objectives in their assessment and evaluation. The scores obtained for each of these indicators contributes to the overall grade/rank obtained in accreditation, rankings and ratings. For instance, the Revised Accreditation Framework 2017 (RAF) of the NAAC has 70 percent weightage for data submitted and 30 percent for peer judgment. Similarly, other rankings and rating methodologies have 50-90 percent weightage for data. These methodologies are often exposed to criticisms from the academia that there is very little flexibility and adaptability to measure their unique best practices followed by HEIs, locally. Some of the best practices, such as interactive classroom sessions, remedial classes, etc., which enhance the learning experiences of students, are not taken into account by the assessment methodologies. Further, additional roles and responsibilities of faculty members in managing administrative activities, for instance in addition to teaching they are engaged as in self-directed roles as career advisors, take voluntary responsibilities to be available students beyond formal contact hours, etc., are not reflected in assessment methodologies, hence, ignored from the overall pursuit of excellence. Additionally, student experiences of what they actually learn beyond the curriculum, activities they involve, moral support received from faculty and peers, how well they are preparing for their career and higher studies, engagement with regional or local communities to bring awareness in social and environmental issues and its impacts on learning outcomes cannot be quantified, hence are left out. Such subjective attributes or values practiced by each of the stakeholders in their unique ways are often overlooked by ranking, rating and accreditation methodologies.

\section{Excellence with Relevance}

Education is an instrument of social change and mobility, the institutions in India have the onus of empowering and emancipating women, learners from marginalized communities; and so on. Additionally, the Indian higher education system which is further complicated given the existing system of affiliation. The majority of the students are first-generation learners coming from diverse socio-economic, linguistic, rural backgrounds. These students 
represent the internal and active stakeholders of affiliated colleges and institutions (around 78 percent of students in India are studying in such colleges). Thus, the HEIs have focused on excellence from a student-centric perspective; hence teaching has been predominantly prioritized; while activities of research and extensions have taken the back seat, Given this current scenario the existing global and national accreditation, rankings and rating models may not be useful to measure excellence and could fall short of capturing the local, regional perceptions, perspectives and practices of excellence across the HEIs

In India, every HEI wants to be a world-class university, but none of the HEIs knows what excellence is. Thus, the best way is to assess their excellence. However, it is a known fact that there is no universal recipe for excellence; there might be some generic conceptions. We must not lose sight of that fact are several parallel pathways to excellence, and again, we must be flexible enough to recognize each of these pathways leading towards excellence. An absolute guiding principle for world-class university may not be useful because of specific challenges that are specific to the Indian context. At the same time, it is important to be cognizant of myriad institution-specific interpretations regarding excellence and the means to pursue the same. Thus, HEIs do not need to get stuck on getting an international ranking, but to look at some of the innovations that are happening in the country, some of them are unique (Altbach, 2003).

Historically, India has a long and admired reputation for higher education. In ancient times, universities of Takshila (now in Pakistan), Nalanda (in the present-day condition of Bihar) and Ujjaini (in modern Madhya Pradesh) were present. They were renowned and captured the attention of students from India, Central Asia, China and South-East Asia and considered as world-class universities. After the diminishing of these universities, the British raj established modern formal university education. Post-independence, it continued to grow in response to expanding demand for access to higher education, giving birth to a large number of teaching centric HEIs. Thus measuring them on criteria of excellence based on international ranking, rating and accreditation might not be appropriate to the local context. The pursuit of excellence across HEIs ought to be a thoughtful balance between local and global aspirations and practice.

\section{Conclusion}

Quality evaluations often emphasize on meeting the objectives, documentation and using institutional quality mechanisms to maintain standards. Further, the meaning of excellence has been a bone-of-contention in Higher Education. Elton (1992) opines that the quality "E's: Empowerment, Enthusiasm, Expertise and Excellence well defines the overall quality of HEIs. Harvey and Green (1993) have described five distinct, interconnected paths to define quality. They are excellence, consistency, the fitness of purpose, value for money 
and transformation. For the government, factors such as efficiency, cost-effectiveness, stakeholder satisfaction, accountability, Similarly, for institutions, quality, of course, learning process, outcomes, management and staffing, while for students cost, accessibility and career opportunities can be measures of quality (Borden and Bottrill, 1994).

The paper indicates the limitations of global and national rating, ranking and accreditation methodology. There is a need to evolve the methodology to appreciate both quantitative and qualitative indices and while appreciating the diversity and distinctiveness of HEIs and its milieu. The system should recognize a broad range of indicators across teaching and learning, research, innovation, engagement, etc.

The draft National Education Policy (2019) attempts to develop a balance between freedom and regulation, between autonomy and decentralization on the one hand, and gentle guidance and resource allocation on the other. It is not a simple task. However, if implemented correctly, this can evolve as the ideal model of the relationship between the government and autonomous educational institutions. As a way forward, devising and implementing quality mechanisms that encourage HEIs to collect data, which will enable them to measure progress in critical areas and establish benchmarks. Accurate, timely and relevant data can be of great assistance in timely decision making. Thus, fostering them to become world-class in the local context.

\section{References}

Agarwal, P. (2007). Higher education in India: Growth, concerns and change agenda. Higher Education Quarterly, 61(2), 197-207.

All India Survey on Higher Education (AISHE) (2019). Report of the Ministry of Human Resource Development (MHRD), Department of Higher Education, Government of India, New Delhi.

Altbach, P. (2003). The costs and benefits of world-class universities. International higher education, (33).

Bekhradnia, B. (2016). International university rankings: For good or ill?. Oxford: Higher Education Policy Institute.

Borden, V. M., \& Bottrill, K. V. (1994). Performance indicators: History, definitions, and methods. New directions for institutional research, 1994(82), 5-21.

Elton, L. (1992). Quality enhancement and academic professionalism. The New Academic, 1 (2), pp 3-5

Goel, A., \& Goel, S. L. (2010). Quality and Excellence in Higher Education (Vol. 2). Deep and Deep Publications.

Harvey, L., \& Green, D. (1993). Defining quality assessment and evaluation in higher education no. 18 (1), London. 
Hazelkorn, E. (2012). European "transparency instruments": Driving the modernisation of European higher education. In European Higher Education at the Crossroads (pp. 339360). Springer, Dordrecht.

Hazelkorn, E., Loukkola, T., \& Zhang, T. (2017). Rankings in Institutional Strategies and Processes: Impact or Illusion?, Bruselas, The European University Association.

University Grants Commission. (2003). Higher Education in India: Issues, Concerns and New Directions. Recommendations of UGC Golden Jubilee Seminars-2003 Held at Eleven Universities in India.

Li, M., \& Chen, Q. (2011). Globalization, internationalization and the world-class university movement: The China experience. A handbook of globalization and higher education, 241-255.

Lomas, L. (2004). Embedding quality: the challenges for higher education. Quality Assurance in education.

Martin, M., \& Stella, A. (2007). External Quality Assurance in Higher Education: Making Choices. Fundamentals of Educational Planning 85. International Institute for Educational Planning (IIEP) UNESCO. 7-9 rue Eugene-Delacroix, 75116 Paris, France.

Ramaprasad, A., Singai, C. B., Hasan, T., Syn, T., \& Thirumalai, M. (2016). India's national higher education policy recommendations since independence: An ontological analysis. Journal of Educational Planning and Administration, 30(1), 5-24.

National Knowledge Commission. (2009). National Knowledge Commission. Report to the Nation 2006-2009.

Shaguri, O. R. (2013). Higher Education in India Access, Equity, Quality. In EAN World Congress Scholar. Accessed June (Vol. 13, p. 2018).

Soh, K. (2017). The seven deadly sins of world university ranking: A summary from several papers. Journal of Higher Education Policy and Management, 39(1), 104-115.

Usher, A., \& Savino, M. (2006). A World of Difference: A Global Survey of University League Tables. Canadian Education Report Series. Online Submission. 